\title{
Numerical Simulation of MEMS Technology Integrated in a Small-Caliber Projectile
}

\author{
Akbar $^{1}$, D. Tarwidi' ${ }^{2}$, E.B. Setiawan ${ }^{3}$ \\ Department of Computational Science, School of Computing, Telkom University \\ Jalan Telekomunikasi No. 1 Terusan Buah Batu, Bandung 40257, Indonesia \\ 1akbar_a@icloud.com \\ 22dedetarwidi@telkomuniversity.ac.id \\ 3 erwinbudisetiawan@telkomuniversity.ac.id
}

\begin{abstract}
In this paper, numerical simulation of small-caliber projectile during external ballistic is presented. This work is aimed to find safe location to install microelectromechanical system (MEMS) inside a small-caliber projectile based on history and distribution of temperature. The MEMS technology is applied to increase performance of the projectile and it must be protected from damage due to high temperature during internal and external ballistic. Heat conduction equation in cylindrical domain is used to describe transient temperature of smallcaliber projectile. Finite element method with the appropriate boundary conditions is adopted to solve the heat conduction equation and to obtain temperature distribution inside projectile. Numerical results show that heat transfer behavior of the projectile at any point is greatly affected by the value of thermal conductivity of material while the external convection does not significantly affect to the heat distribution. The maximum temperatures obtained from temperature history are below threshold value of MEMS damage that is $71^{\circ} \mathrm{C}$. The MEMS technology can be installed anywhere inside the projectile except at the rear surface of the projectile which experienced friction with the inner surface of gun barrel during internal ballistics.
\end{abstract}

Keywords: MEMS technology, numerical simulation, small-caliber projectile, finite element method, heat conduction, temperature distribution.

\section{INTRODUCTION}

M ICROELECTROMECHANICAL system (MEMS) technology has emerged since several past decades even though the utilization is still limited. Nowadays, the MEMS technology is used for micro gyros for navigation and positioning, microbolometers for infrared imaging, and micro mirrors for steering laser beams (Keller, 2012). The future of MEMS can be appeared in military defense applications. One of them is integrating MEMS technology into a small-caliber projectile. In modern projectile, the MEMS technology has already been integrated and is used to increase performance of the projectile. However, it is only used in large-caliber projectile due to large spaces available so that the MEMS is more protected from high temperatures. In small-caliber projectile, installing MEMS technology become harmful because it is only survived until temperature of $71^{\circ} \mathrm{C}(344 \mathrm{~K})$ whereas the surface of projectile can reach temperature of $267^{\circ} \mathrm{C}(540 \mathrm{~K})$ (Thomas \& Dozier, 2010).

To evaluate whether MEMS technology can be applied in small-caliber projectile, it is ideally examined by direct experiment. However, it requires enormous funds and efforts. Hence, some researchers are more interested in conducting numerical simulation. Thomas simulated energy harvesting in smallcaliber projectile (Thomas, 2009). His results show that at least $15 \mathrm{~mW}$ of power can sustain over 60 meters of trajectory. Moreover, Thomas et al. conducted numerical analysis of the utilization of MEMS in a small-caliber projectile (Thomas \& Dozier, 2010). They concluded that MEMS can be applied 
AKBAR ET.AL.

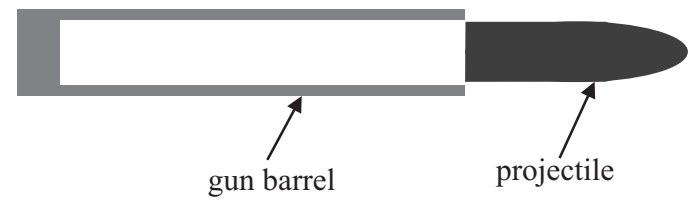

Fig. 1. Illustration of projectile when moving out from gun barrel.

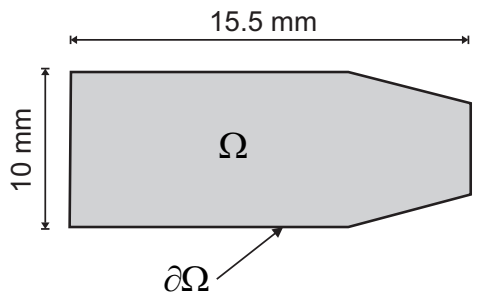

Fig. 2. Domain under study.

in small-caliber projectile because the temperature is always below $56^{\circ} \mathrm{C}$. Further, Nastasescu et al. performed numerical simulation when the projectile moving out from the gun barrel or also called external ballistics (Nastasescu, Cotoara-Nicolae, \& Barbu, 2009). The simulation results were then compared with experimental results and showed accurate results. All simulations that have been conducted in the literatures are using finite element method (FEM).

There are many softwares to simulate physical phenomena occurring in the world. Most of them are developed based on finite element method. One of the powerful softwares to simulate heat transfer in a projectile is FreeFem++ (Hecht, 2012). Some researchers used the software to obtain numerical results. Lefebvre conducted a numerical simulation of fluid-particle using FreeFem++ (Lefebvre, 2007). Moreover, Deriaz et al. used FreeFem++ to study magnetic equations arising in fusion plasma (Deriaz et al., 2011). Furthermore, Dellacherie et al. simulated low mach nuclear core model using FreeFem++ (Dellacherie, Faccanoni, Grec, Nayir, \& Penel, 2014).

In this work, history and distribution of temperature inside a small-caliber projectile during external ballistic is investigated numerically. Further discussion about external ballistics can be found in (Steele, 1994). Transient temperature during external ballistics is modeled by heat conduction equation in a cylindrical domain with appropriate boundary conditions. Numerical results is obtained by using finite element method which is solved by FreeFem++. To the best of our knowledge, there is no research about simulation of MEMS technology in small-caliber projectile using FreeFEM++. The simulation results is evaluated to determine the possibility in applying MEMS technology in small-caliber projectile.

\section{MAThematiCAL Model}

A mathematical model is required to describe heat transfer of projectile during external ballistics, i.e. when the projectile is moving out from the gun barrel and flying to the target. In this model, only heat conduction is considered, while heat convection and radiation are neglected. Fig. 1 illustrates a projectile when moving out from a gun barrel. Since the projectile is similar to cylinder shape, then cylinder coordinate is considered or it will be represented in $r-z$ plane where $r$ and $z$ are radial and axial axes respectively. Suppose $T(r, z, \psi, t)$ is temperature at position $(r, z, \psi)$ and time $t$. Heat conduction equation of projectile in cylindrical coordinate can be formulated as

$$
\rho c \frac{\partial T}{\partial t}=\frac{1}{r} \frac{\partial}{\partial r}\left(k r \frac{\partial T}{\partial r}\right)+\frac{1}{r^{2}} \frac{\partial^{2} T}{\partial \psi^{2}}+\frac{\partial}{\partial z}\left(k \frac{\partial T}{\partial z}\right),
$$

where $\rho, c$, and $k$ are density $\left(\mathrm{kg} / \mathrm{m}^{3}\right)$, specific heat $(\mathrm{J} / \mathrm{kg} / \mathrm{K})$, and thermal conductivity $\left(\mathrm{W} / \mathrm{m}^{2} / \mathrm{K}\right)$ of material. 
Heat source in this case comes from friction between outer surface of projectile and inner surface of gun barrel during internal ballistics (when the projectile is still in the gun barrel). In this study, it is assumed that heat generated by the friction is uniform so that the heat will propagate in axially symmetric toward cylinder axis. As a result, $\partial T / \partial \psi=0$ and temperature only depends on variable $r, z$, and $t$ or it is written as $T(r, z, t)$. Further, the thermal conductivity is assumed constant in the whole domain. Let $\Omega$ be domain under study, see Fig. 2. Therefore, (1) can be simply presented as (Blomberg, 1996)

$$
\frac{\partial T}{\partial t}=\frac{\alpha}{r} \frac{\partial}{\partial r}\left(r \frac{\partial T}{\partial r}\right)+\alpha \frac{\partial}{\partial z}\left(\frac{\partial T}{\partial z}\right)
$$

where $\alpha=k / \rho c$ is thermal diffusivity $\left(\mathrm{m}^{2} / \mathrm{s}\right)$ of the material. For the purpose to obtain weak form, (2) is multiplied by $r$, yields

$$
r \frac{\partial T}{\partial t}-\alpha \frac{\partial}{\partial r}\left(r \frac{\partial T}{\partial r}\right)-\alpha \frac{\partial}{\partial z}\left(r \frac{\partial T}{\partial z}\right)=0 .
$$

Initial temperature of the whole domain is assumed uniform and denoted by $T_{0}$ so that

$$
T(r, z, 0)=T_{0} \text {. }
$$

Moreover, the boundary condition in this case is only considered as convective flux. It is formulated as (Alexiades \& Solomon, 1992)

$$
k \frac{\partial T}{\partial \mathbf{n}}(r, z, t)=h\left(T_{\infty}-T(r, z, t)\right),
$$

where $\mathbf{n}$ is outward normal vector to the boundary $(\partial \Omega), h$ is convective heat transfer coefficient $\left(\mathrm{J} / \mathrm{m}^{2} / \mathrm{s} / \mathrm{K}\right)$, and $T_{\infty}$ is the temperature of surrounding environment. Here, the boundary condition represents Newton's law of cooling.

\section{NUMERICAL METHOD}

To solve the partial differential equation in (3) with the initial condition (4) and the boundary condition (5) analytically is a very difficult problem. Therefore, in this study, numerical solution using finite element method is adopted to solve this problem. One of the powerful software to solve partial differential equation is FreeFem++ (Hecht, 2012). However, to use FreeFem++, the user must understand step by step of finite element method which requires deep mathematical understanding.

Some of the important steps that must be understood before writing FreeFem++ code in the computer can be described as follows. First, determine the domain and its boundary. In this case, the boundary is divided into several sections and each section is represented by a parametric equation. Second, discretize the domain $\Omega$ by generating small triangles known as triangulation. Fig. 3(a) shows triangulation of the domain using FreeFem++. The third is the most difficult step, i.e. derive the variational formulation or known as weak form of (3). To obtain a weak form of the problem, perform the following steps. Multiply (3) with a test function $w=w(r, z)$ and integrate over $\Omega$. It reads

$$
\int_{\Omega} \frac{\partial T}{\partial t} w r d r d z-\int_{\Omega} \alpha \frac{\partial}{\partial r}\left(r \frac{\partial T}{\partial r}\right) w d r d z-\int_{\Omega} \alpha \frac{\partial}{\partial z}\left(r \frac{\partial T}{\partial z}\right) w d r d z=0 .
$$

Then, use integration by parts to obtain (Font \& Peria, 2013)

$$
\int_{\Omega} \frac{\partial T}{\partial t} w r d r d z-\int_{\partial \Omega} \alpha \frac{\partial T}{\partial \mathbf{n}} w r d \Gamma+\int_{\Omega} \alpha(\nabla T \cdot \nabla w) r d r d z=0 .
$$

Finally, substitute the boundary condition (5) into (7). It yields

$$
\int_{\Omega}\left(\frac{\partial T}{\partial t} w+\alpha \nabla T \cdot \nabla w\right) r d r d z+\int_{\partial \Omega} h /(\rho c)\left(T-T_{\infty}\right) w r d \Gamma=0 .
$$

Equation (8) is the weak form of (3). Further, the implicit Euler scheme is used to discretize time variable. Suppose $\Delta t=t_{\max } / N$ where $N$ is an integer. Let $T^{n}=T\left(r, z, t^{n}\right)$ with $t^{n}=n \Delta t, 0 \leq n \leq N$. Then, the approximation of $\partial T / \partial t$ is

$$
\frac{\partial T}{\partial t} \approx \frac{T^{n}-T^{n-1}}{\Delta t}
$$


AKBAR ET.AL.

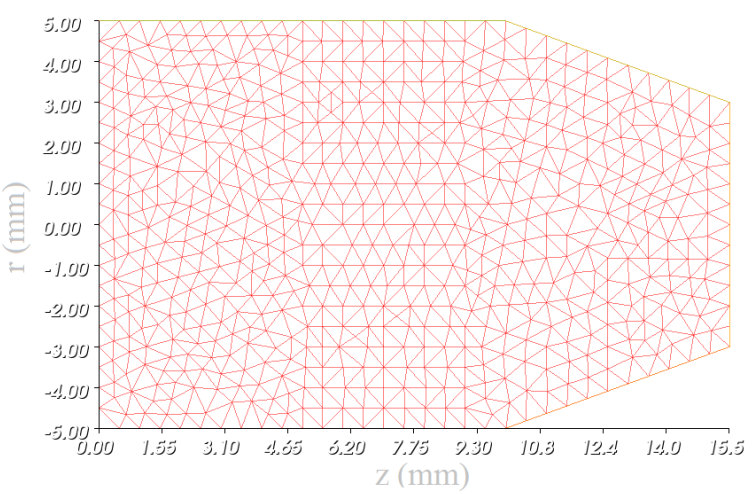

(a)

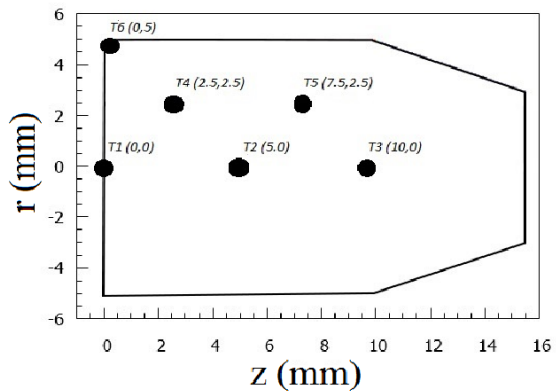

(b)

Fig. 3. (a) finite element discretization; (b) Six selected points inside projectile to evaluate temperature history.

Substituting this formula into (8). It becomes

$$
\int_{\Omega}\left(\frac{T^{n}-T^{n-1}}{\Delta t} w+\alpha \nabla T^{n} \cdot \nabla w\right) r d r d z+\int_{\partial \Omega} h /(\rho c)\left(T^{n}-T_{\infty}\right) w r d \Gamma=0 .
$$

Equation (10) is the discrete weak formulation which is an input for FreeFem++. More discussion about finite element method can be found in some literatures (Wilson \& Nickell, 1966), (Lewis, Morgan, Thomas, \& Seetharamu, 1996), (Reddy \& Gartling, 2010).

\section{RESUlTS AND Discussion}

In this section, numerical simulation of heat transfer in the projectile to examine the possibility to install MEMS technology is presented. In this simulation, pure lead is assumed as projectile material and the projectile has $10 \mathrm{~mm}$ in caliber. The initial temperature of projectile is assumed $293 \mathrm{~K}$. The other parameters of the simulation are summarized in Table I. Here, temperature distribution and temperature history of projectile during external ballistics will be evaluated to determine whether MEMS can be installed in small-caliber projectile. It is also presented the behavior of temperature distribution and temperature history if the physical properties such as thermal conductivity and external convection change about $\pm 25 \%$.

\section{A. Numerical Results of Temperature Distribution}

Temperature distribution in the projectile for $t=0, t=0.145$, and $t=0.289$ seconds with some changes of thermal conductivity and external convection is depicted in Fig. 4. External ballistics is started when the projectile is moving out from gun barrel and flying to the target. Temperature distribution of the projectile at $t=0$ seconds (just after leaving out gun barrel) is shown by image on top left of Fig. 4. As can be seen that the surface of projectile has very high temperature about $547 \mathrm{~K}$ while inside projectile the temperature is still $293 \mathrm{~K}$. This high temperature because the surface of projectile experiences friction with the gun barrel by very high speed. Images on the first row from top in Fig. 4 also reveal that at $t=0.145$ seconds, heat from surface of projectile is diffused throughout the projectile with the highest temperature at $304 \mathrm{~K}$ occurring near heat source. Further, at $t=0.289$ seconds ( 40 meters of trajectory), the effect of heat source on projectile surface is decreasing due to external convection from moving air so that the temperature of projectile is gradually cooling down.

Images on the second row from top in Fig. 4 display temperature distribution with thermal conductivity and external convection increased by $25 \%$. It can be seen that the rate of heat transfer is faster than without change of parameters. As consequence, by raising up these properties, it can increase the risk of MEMS damage. Similarly, by decreasing external convection by $25 \%$ while the thermal conductivity increasing 

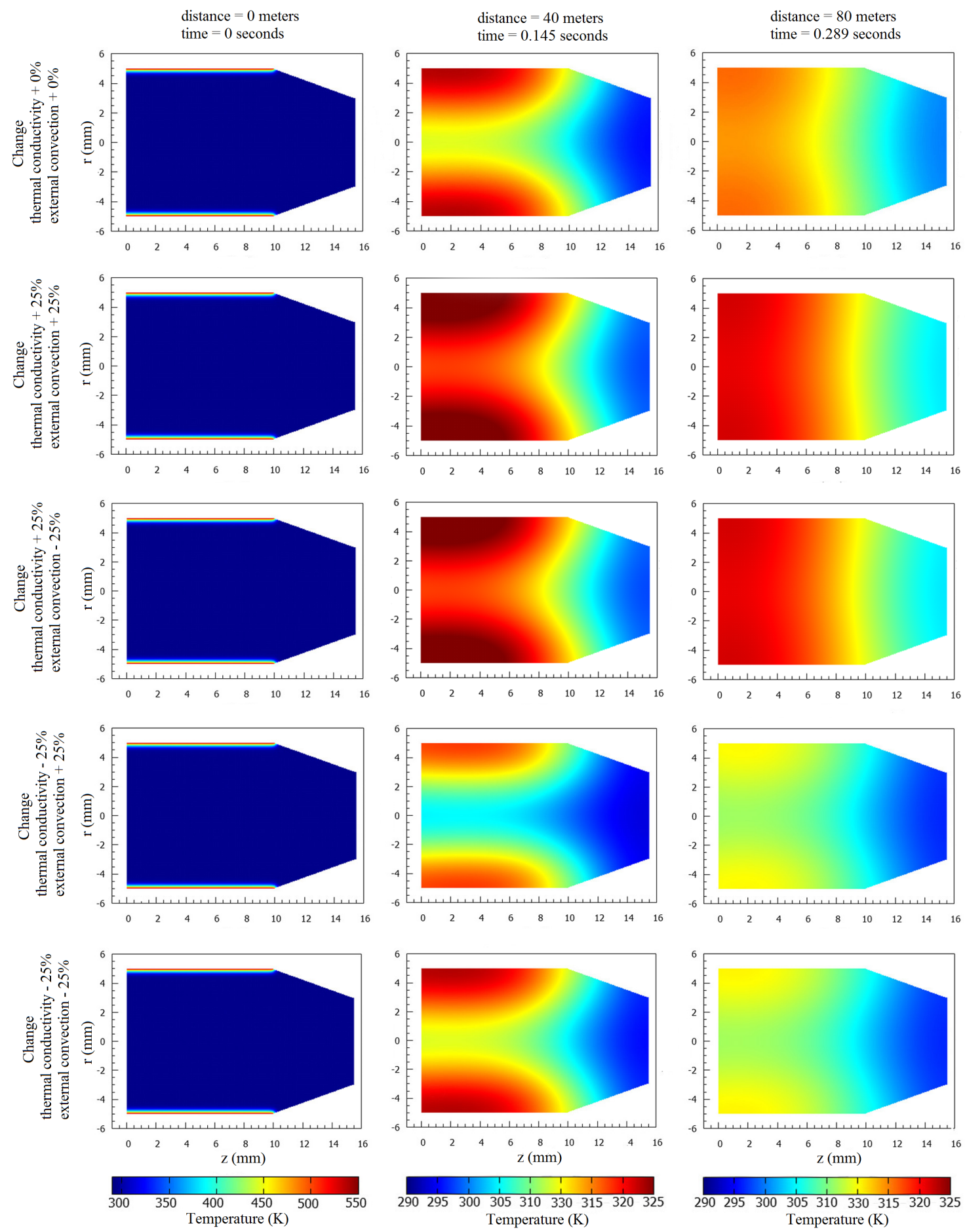

Fig. 4. Temperature distribution of the projectile for $t=0$ seconds ( 0 meters), $t=0.145$ seconds ( 40 meters), and $t=0.289$ seconds (80 meters) with change of material thermal conductivity and external convection. 
AKBAR ET.AL.

TABLE I

PARAMETERS OF THE SIMULATION.

\begin{tabular}{clll}
\hline \hline symbol & parameter & value & unit \\
\hline$\rho$ & density of lead & 11340 & $\mathrm{~kg} / \mathrm{m}^{3}$ \\
$c$ & specific heat of lead & 125.6 & $\mathrm{~J} / \mathrm{kg} / \mathrm{K}$ \\
$k$ & thermal conductivity of tin & 35 & $\mathrm{~W} / \mathrm{m} / \mathrm{K}$ \\
$h$ & external convection coefficient & 507 & $\mathrm{~W} / \mathrm{m}^{2} / \mathrm{K}$ \\
$T_{0}$ & initial temperature & 293 & $\mathrm{~K}$ \\
$T_{\infty}$ & surrounding environment temperature & 293 & $\mathrm{~K}$ \\
\hline \hline
\end{tabular}

by $25 \%$, the numerical results are almost the same as described by the third row of Fig. 4 . It means that the change of external convection has not influenced significantly to heat transfer behavior.

Temperature distribution with thermal conductivity decreased by $25 \%$ and external convection increased by $25 \%$ is presented by images in the fourth row of Fig. 4 . As predicted, the rate of heat transfer is slower than without change of the parameters. It can be said that the lower thermal conductivity of material the better choice to install MEMS technology. Further, images on the fifth row of Fig. 4 shows the similar results with the temperature distribution of the fourth row as predicted that the external convection has small influence to heat transfer rate. These numerical results confirm with the simulation results that had been done by (Thomas \& Dozier, 2010).

\section{B. Numerical Results of Temperature History}

Temperature history of some selected points in small-caliber projectile is studied. Here, six points inside projectile are selected to examine the temperature history during external ballistics. The six selected points are illustrated in Fig. 3(b). These points are selected because of its potential to place MEMS. Point $T_{1}$, $T_{2}$, and $T_{3}$ are points on core part of the projectile. Point $T_{5}$ is a point between core and surface of projectile while point $T_{6}$ is a point on the surface of projectile.

Temperature history of the six selected points are shown in Fig. 5. As can be seen from the figure, point $T_{1}, T_{2}$, and $T_{3}$ have maximum temperature of $319 \mathrm{~K}, 317 \mathrm{~K}$, and $308 \mathrm{~K}$. All these temperature are below $344 \mathrm{~K}$ so that it is safe to install MEMS at these points. Point $T_{4}$ and $T_{5}$ have increased rapidly until maximum temperature of $320 \mathrm{~K}$ and $314 \mathrm{~K}$ respectively. Although these points are below $344 \mathrm{~K}$ which is safe to place MEMS but they have more risk for damaged than three points before. The different results is depicted by point $T_{6}$ where it decreases from high temperature $547 \mathrm{~K}$ to $320 \mathrm{~K}$. This high temperature is because of friction between projectile surface and gun barrel. Then, when external ballistics occurs, the temperature of surface is cooling down because external convection. Therefore, at point $T_{6}$, it is impossible to install MEMS because it will damage the MEMS.

Fig. 6 reveals temperature history of the selected points with change of parameters whereas the maximum temperature reached of these points is listed in Table II. It can be seen that with change of thermal conductivity by $\pm 25 \%$, it has impacted significantly to rate of heat transfer while the change of external convection has small influence to rate of heat transfer. From Table II, it can be seen that by increasing thermal conductivity by $25 \%$, it has increased the maximum temperature by $1.2 \%$ to $3.2 \%$. In contrast, by decreasing thermal conductivity by $25 \%$, it has decreased the maximum temperature by $0.95 \%$ to $2.5 \%$. These results does not valid for point $T_{6}$ where there is no change of maximum temperature. It can be seen that these results are a step head compared with numerical simulation which was presented by (Thomas \& Dozier, 2010). Here, numerical results are evaluated not only based on temperature distribution but also based on temperature history.

\section{CONCLUSION}

Numerical simulation of temperature distribution and temperature history of small-caliber projectile to examine the possibility to install MEMS technology inside the projectile has been successfully conducted by finite element method which is implemented by FreeFem++ software. Temperature distribution in 
(a)

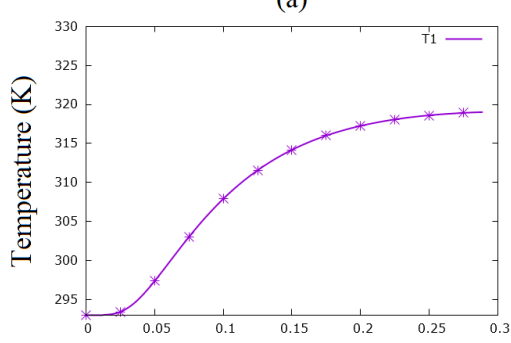

(d)

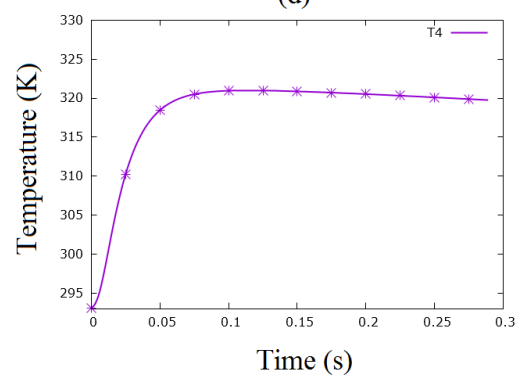

(b)

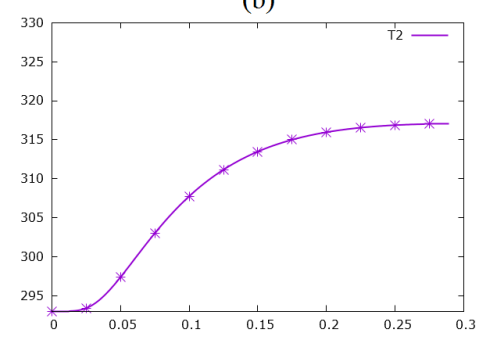

(e)

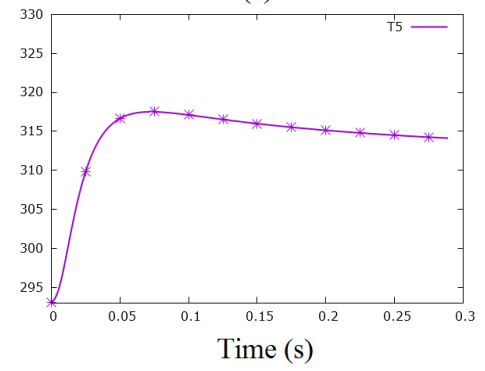

(c)

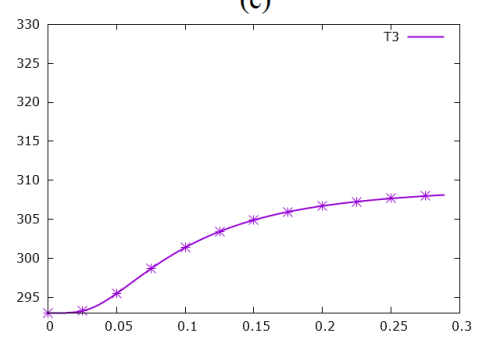

(f)

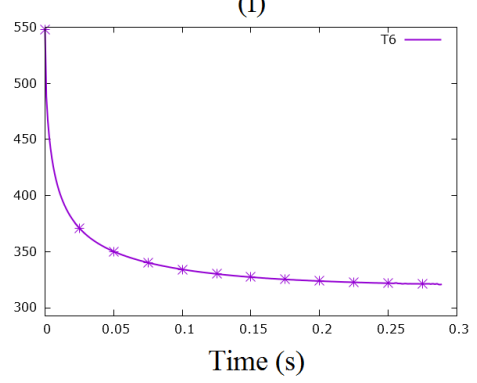

Fig. 5. (a) - (f) Temperature history of point $T_{1}, T_{2}, \ldots, T_{6}$ respectively.

(a)

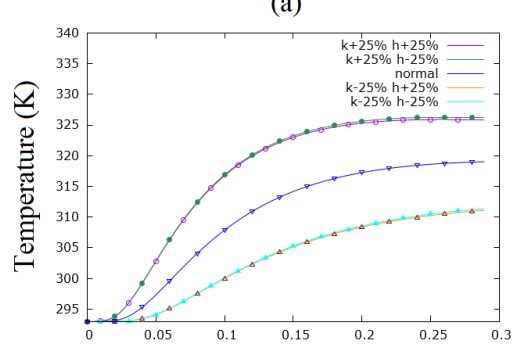

(d)

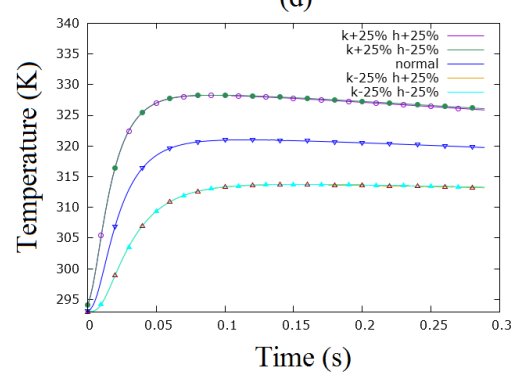

(b)

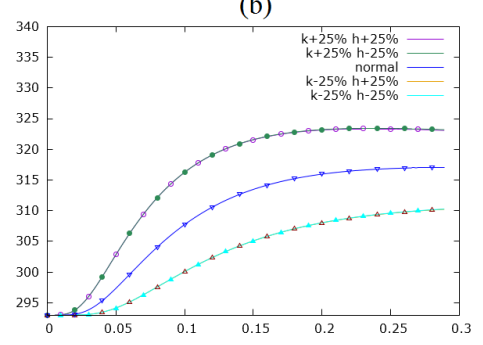

(e)

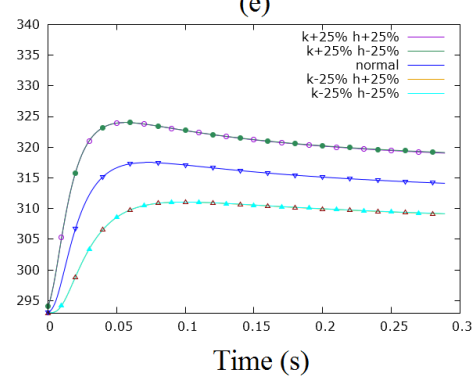

(c)

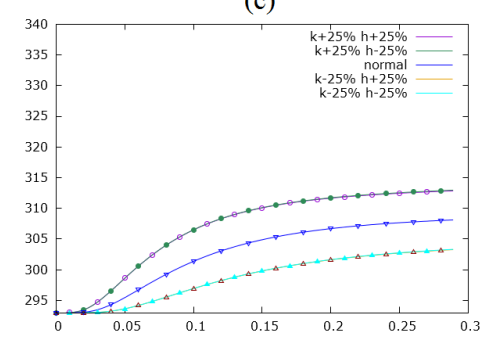

(f)

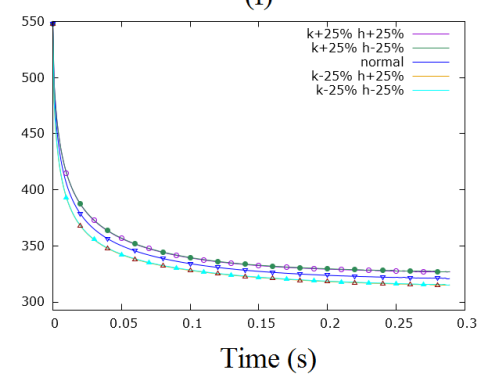

Fig. 6. (a) - (f) Temperature history of point $T_{1}, T_{2}, \ldots, T_{6}$ respectively with change of material thermal conductivity and external convection.

projectile has been obtained by plotting temperatures in each point. According to heat distribution of the projectile during external ballistics, it has been shown that heat transfer behavior of the projectile at any point is greatly affected by the value of thermal conductivity of material while the external convection does not significantly effect to the heat distribution. In addition, by considering temperature history of the selected points, it has been concluded that by increasing thermal conductivity by $25 \%$, it has increased the maximum temperature of the selected points by $1.2 \%$ to $3.2 \%$ whereas by decreasing thermal conductivity by $25 \%$, it has decreased the maximum temperature by $0.95 \%$ to $2.5 \%$ except for 
AKBAR ET.AL.

TABLE II

MAXIMUM TEMPERATURE OF TEMPERATURE HISTORY AT SIX SELECTED POINTS.

\begin{tabular}{lcccccc}
\hline \hline physical properties & $T_{1}(\mathrm{~K})$ & $T_{2}(\mathrm{~K})$ & $T_{3}(\mathrm{~K})$ & $T_{4}(\mathrm{~K})$ & $T_{5}(\mathrm{~K})$ & $T_{6}(\mathrm{~K})$ \\
\hline thermal conductivity $+25 \%$, external convection $+25 \%$ & 325 & 323 & 312 & 328 & 324 & 547 \\
thermal conductivity +25\%, external convection $-25 \%$ & 326 & 323 & 312 & 328 & 324 & 547 \\
thermal conductivity $-25 \%$, external convection $+25 \%$ & 311 & 310 & 303 & 313 & 311 & 547 \\
thermal conductivity -25\%, external convection -25\% & 311 & 310 & 303 & 313 & 311 & 547 \\
\hline \hline
\end{tabular}

points next to projectile surface. These maximum temperatures are below threshold value of MEMS damage that is $71^{\circ} \mathrm{C}$. Therefore, the MEMS technology can be installed anywhere inside the projectile except at the rear surface of the projectile which experienced friction with inner surface of gun barrel during internal ballistics. Suggestion for the future research is conducting numerical simulation both internal and external ballistics and validating the numerical results with the experimental results.

\section{REFERENCES}

Alexiades, V., \& Solomon, A. D. (1992). Mathematical modeling of melting and freezing processes. CRC Press.

Blomberg, T. (1996). Heat conduction in two and three dimensions: Computer modelling of building physics applications (Vol. 1008). Lund University.

Dellacherie, S., Faccanoni, G., Grec, B., Nayir, E., \& Penel, Y. (2014). 2d numerical simulation of a low mach nuclear core model with stiffened gas using freefem++. ESAIM: Proceedings and Surveys, 45, 138-147.

Deriaz, E., Despres, B., Faccanoni, G., Gostaf, K. P., Imbert-Gérard, L.-M., Sadaka, G., \& Sart, R. (2011). Magnetic equations with freefem++: the grad-shafranov equation \& the current hole. In Esaim: Proceedings (Vol. 32, pp. 76-94).

Font, R., \& Peria, F. (2013). The finite element method with freefem++ for beginners. Electronic Journal of Mathematics \& Technology, 7(4).

Hecht, F. (2012). New development in freefem++. J. Numer. Math., 20(3-4), 251-265.

Keller, J. (2012). Mems and nanotechnology maturing for certain military applications, but the potential is still immense. Military and Aerospace Electronics, 23(6), 27-28.

Lefebvre, A. (2007). Fluid-particle simulations with freefem++. In Esaim: Proceedings (Vol. 18, pp. 120-132).

Lewis, R. W., Morgan, K., Thomas, H., \& Seetharamu, K. (1996). The finite element method in heat transfer analysis. John Wiley \& Sons.

Nastasescu, V., Cotoara-Nicolae, A., \& Barbu, C. (2009). Using of the finite element method in exterior ballistics. Scientific Bulletin-Nicolae Balcescu Land Forces Academy, 14(2), 111.

Reddy, J. N., \& Gartling, D. K. (2010). The finite element method in heat transfer and fluid dynamics. CRC press.

Steele, B. D. (1994). Muskets and pendulums: Benjamin robins, leonhard euler, and the ballistics revolution. Technology and Culture, 35(2), 348-382.

Thomas, M. B. (2009). Thermoelectric energy harvesting in small-caliber projectiles. Technical Digest PowerMEMS 2009 (Washington DC, USA, December 1-4 2009), 261-264.

Thomas, M. B., \& Dozier, L. (2010). Finite element modeling of transient temperatures in a small-caliber projectile. Am. J. Eng. Applied Sci, 3, 355-362.

Wilson, E. L., \& Nickell, R. E. (1966). Application of the finite element method to heat conduction analysis. Nuclear Engineering and Design, 4(3), 276-286. 